Article

\title{
Financial literacy, financial capabilities, and sustainable business model practice among small business owners in Nigeria
}

- August 2021

- Journal of Sustainable Finance \& Investment

DOI:10.1080/20430795.2021.1962663

Authors:

$\underline{\text { Abiola Babajide }}$

Evans Osabuohien

Patience Tunji-Olayeni

Hezekiah Falola

Lanre Amodu

Felicia Omowunmi Olokoyo

Folashade Adegboye

Benjamin Ehikioya

References (54)

\section{Abstract}

The study investigates how financial literacy and financial capabilities influence small firms' sustainability in Lagos and Ogun States, Nigeria. It employs a survey research design to collect data from 300 small business owners across the two States. Data collected were analysed using Structural Equation Modelling (SEM) technique. The study shows that environmental sustainability, financial sustainability and social responsibility are significant determinants of small firms' sustainability in Nigeria. Financial literacy and financial capabilities practices also have a significant positive impact on firm sustainability. However, the use of savings product shows a significant adverse effect on firms' sustainability. The findings imply that financial literacy knowledge and practice in small business operations enhance firms' sustainability. The study recommends that small firms should incorporate sustainability models into their 
business operations and improve their financial knowledge to maintain sustainability. Small business owners should also invest their savings in an appropriate investment product that suits their risk tolerance.

\section{Citations (2)} References (54)

Corporate environmental performance, climate change mitigation, and green innovation behavior in sustainable finance

Article

- Jan 2021 